\title{
Warfarin or aspirin after mitral valve repair: Why work harder?
}

\author{
Leonid Sternik, MD
}

\author{
From the Department of Cardiac Surgery, Sheba Medical Center, Tel-Hashomer, Israel. \\ Disclosures: Author has nothing to disclose with regard to commercial support. \\ Received for publication Dec 29, 2015; accepted for publication Dec 30, 2015; available ahead of print Jan 29, \\ 2016. \\ Address for reprints: Leonid Sternik, MD, Department of Cardiac Surgery, Sheba Medical Center, Tel-Hashomer, \\ Israel 52621 (E-mail: leosternik@hotmail.com). \\ J Thorac Cardiovasc Surg 2016;151:1309-10 \\ $0022-5223 / \$ 36.00$ \\ Copyright (C 2016 by The American Association for Thoracic Surgery \\ http://dx.doi.org/10.1016/j.jtcvs.2015.12.044
}

There is no clear answer to the question of which antithrombotic therapy should be prescribed after mitral valve repair (MVr). One decade ago, Vaughan and colleagues ${ }^{1}$ reported that $64 \%$ of surgeons in the United Kingdom used warfarin for 6 months after MVr, and 54\% used aspirin for the long term. Vaughan and colleagues ${ }^{1}$ complained about the absence of existing guidelines for anticoagulation after MVr. On the other hand, Meurin and associates ${ }^{2}$ showed that thromboembolic events during the first 6 weeks after MVr are significant and can reach $3.5 \%$, even among patients in sinus rhythm. The only risk factor for a thromboembolism was the absence of antithrombotic therapy. Recent guidelines for antithrombotic therapy after $\mathrm{MVr}$ have been controversial. European guidelines in 2012 (class IIa, level C), recommended vitamin $\mathrm{K}$ antagonist (VKA) for the first 3 months after MVr. ${ }^{3}$ Also in 2012, the American College of Chest Physicians opted for antiplatelet therapy (grade $2 \mathrm{C}$ ). ${ }^{4}$

Paparella and colleagues, ${ }^{5}$ as reported in their article in this issue of the Journal carried out an extensive retrospective study, performed at 19 centers in 5 countries. Paparella and colleagues ${ }^{5}$ are to be congratulated for this exhaustive and important work. They compared a group of 1517 patients receiving warfarin after $\mathrm{MVr}$ with another group of 365 patients being treated with aspirin after the same procedure. They found comparable efficacy in preventing arterial embolism but significantly less bleeding complication and even mortality in the group being treated with aspirin. Paparella and colleagues ${ }^{5}$ did also point out some weaknesses of this work. The study was retrospective, and international normalized ratio (INR) and management data were missing.

Both groups were retrospectively matched; however, I found it significant that a statistical difference between the groups was found to be more frequent use of a complete ring in the warfarin-treated group. A complete ring adds more than $50 \%$ to the prosthetic material and knots relative to an incomplete ring, simply because the complete ring has a longer circumference. In this study, patients treated with aspirin received more artificial chordae, but thrombi on artificial (usually polytetrafluoroethylene) chordae are unusual.

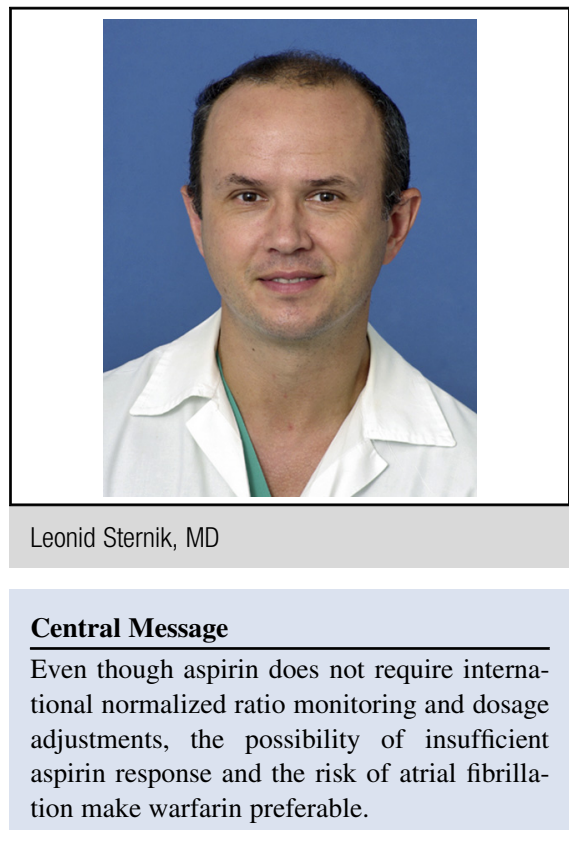

See Article page 1302.

On the other hand, the presence of more prosthetic material in the atrium in the warfarin-treated group with the same results in terms of prevention of thromboembolism calls into question the equivalent antithrombotic efficacy of warfarin and aspirin.

Paparella and colleagues ${ }^{5}$ found a statistically higher amount of major bleeding and mortality rate in the warfarin-treated group. As previously mentioned, the limitations of this study were missing data on INR management, patient comorbidities and compliance, and contraindications to VKA. Perhaps the higher bleeding rate is attributable to mismanagement of VKA treatment and could be improved with more careful monitoring of INR and better consideration of contraindications for this treatment.

Probably we must consider more than the prevention of arterial embolism during the first 6 months after surgery. The target goal, for the first 3-month period after MVr, stems from the need for endothelialization of prosthetic rings and knots and atrial suture lines. Incomplete endothelialization can cause blood clot formation on the ring and even endocarditis. We must keep in mind that the left atrium has relatively slower blood flow. Ventricular function and left atrial size can influence blood flow in the area adjacent to the prosthetic ring. This is why complete endothelialization of the ring and knots is so 
important, and factors such as ventricular function and atrial size must be taken into consideration when deciding on antithrombotic treatment after MVr. Another issue is aspirin resistance. Vivas and colleagues have reported that it occurs in as many as $65 \%$ of patients. Special studies are needed to investigate platelet function and patient response to aspirin. ${ }^{6}$ Within 3 to 6 months after cardiac surgery, many patients have atrial fibrillation develop. ${ }^{7}$ Some patients and physicians are not aware of "silent" episodes of atrial fibrillation. Patients with atrial fibrillation episodes would be better protected by VKA.

Naturally, it is easy and convenient to prescribe aspirin and feel that the patient is protected. No INR tests are needed, and no decision must be made about warfarin dosage. But easy does not always imply good. The high frequencies of patients with insufficient response to aspirin and of silent episodes of atrial fibrillation appear to make VKA treatment a better option. We must, however, work harder with VKA. We must search for contraindications to this treatment, as well as monitoring patient compliance. We must be careful with old and fragile patients; INR management must be meticulous.

I conclude that the significant numbers of patients with insufficient response to aspirin and of instances of postoperative atrial fibrillation make warfarin treatment preferable to aspirin. The potential for bleeding complications, however, dictates careful management of INR and evaluation of patient-specific considerations, such as contraindication to VKA, compliance with treatment, and fragility.

We must wait for further prospective, randomized studies to decide which antithrombotic treatment is better after MVr. The treatment may be tailored to the patient.

\section{References}

1. Vaughan P, Waterworth PD. An audit of anticoagulation practice among UK cardiothoracic consultant surgeons following valve replacement/repair. J Heart Valve Dis. 2005; 14:576-82.

2. Meurin P, Tabet JY, Iliou MC, Pierre B, Corone S, Cristofini P, et al; Working Group of Cardiac Rehabilitation of the French Society of Cardiology. Thromboembolic events early after mitral valve repair: incidence and predictive factors. Int J Cardiol. 2008;126:45-52.

3. Vahanian A, Alfieri O, Andreotti F, Antunes MJ, Barón-Esquivias G, Baumgartner $\mathrm{H}$, et al; ESC Committee for Practice Guidelines. Guidelines on the management of valvular heart disease (version 2012): the Joint Task Force on the Management of Valvular Heart Disease of the European Society of Cardiology (ESC) and the European Association for Cardio-Thoracic Surgery (EACTS). Eur Heart J. 2012;33:2451-96.

4. Whitlock RP, Sun JC, Fremes SE, Rubens FD, Teoh KH. American College of Chest Physicians. Antithrombotic and thrombolytic therapy for valvular disease: antithrombotic therapy and prevention of thrombosis, 9th ed: American College of Chest Physicians evidence-based clinical practice guidelines. Chest. 2012; 141(2 Suppl):e576S-600.

5. Paparella D, Di Mauro M, Worms KB, Bolotin G, Russo C, Trunfio S, et al; GIROC Investigators. Antiplatelet versus oral anticoagulant therapy as antithrombotic prophylaxis after mitral valve repair. J Thorac Cardiovasc Surg. 2016;151: 1302-8.e1.

6. Vivas D, Bernardo E, García-Rubira JC, Azcona L, Núñez-Gil I, GonzálezFerrer JJ, et al. Can resistance to aspirin be reversed after an additional dose? J Thromb Thrombolysis. 2011;32:356-61.

7. Lomivorotov VV, Efremov SM, Pokushalov EA, Karaskov AM. New-onset atrial fibrillation after cardiac surgery: pathophysiology, prophylaxis, and treatment. $J$ Cardiothorac Vasc Anesth. August 10, 2015 [Epub ahead of print]. 